\title{
A Comparative Study on Properties of Different Grade Bitumen Used in The Transportation Projects in and Around Dhaka City
}

\author{
Md Razibur Rahman ${ }^{*}$, Subrata Chowdhury², Md abdullah ${ }^{2}$, Avijit Sarkar ${ }^{2}$, Saidur Rahman Sayeed ${ }^{2}$ and Md \\ Monoarul Islam Real ${ }^{2}$
}

${ }^{1}$ Department of Civil Engineering, Rajshahi University of Engineering \& Technology (RUET), Bangladesh

${ }^{2}$ Department of Civil Engineering, Stamford University Bangladesh

*Corresponding author: Md Razibur Rahman, Department of Civil Engineering, Rajshahi University of Engineering \& Technology (RUET), Bangladesh

\begin{abstract}
Bangladesh is a developing country as well as the number of populations is too much higher. For fulfilling the demand of people, firstly a good transportation system is necessary for our country. Among the all three modes of transport, (land transport (road, rail), water transport, air transport) roadway is mostly used mode of transport in Bangladesh. Bitumen is one of the main courses of roadway pavement structure. It is used as a binder material.

Bitumen is an oil-based element. It is a semi-solid hydrocarbon product produced by removing the lighter fractions (such as liquid petroleum gas, petrol and diesel) from bulky crude oil during the refining process. As such, it is correctly known as refined bitumen. Bitumen is a mixture of dark, sticky, highly viscous organic liquids composed mainly of aromatic hydrocarbons. It is usually black or dark brown in color. The material behavior is dependent on the ambient temperature. The main objective in this paper is to determine the actual values of different grade bitumen used in and around Dhaka city ,to compare the standard values and actual values of different grade bitumen, to select the perfect types of bitumen which are suitable for our country and finally to provide better surface conditions of roadway.
\end{abstract}

Keywords: Mode of transportation; Bitumen; Pavement; Temperature; Sticky

\section{Introduction}

A better transportation system is significant for a country's upliftment. It is essential for safe, clean and affordable transport. A excellent transportation way diminish the space among people, markets, services and knowledge - or merely 'getting people linked' - which is an eminent segment of what economic growth is all about. Though virtual connectivity has become rising momentous today with the emergence of modern communication avenues, a proper and dependable transport network remains necessary. There is a highly potential positive interrelation between a state's financial promotion and the nature of its road chain.

As Bitumen is a thermoplastic element, its firmness varies with temperature. At presently in utmost states around the Globe, bitumen are graded pursuant to a number of fundamental, and often technological examine. For illustration in UK, penetration and softening point have long been the base of the grading methods. Somewhere else, inevitable substance such as viscosity have also been identified definitely. To date, a lot of alteration on grades of bitumen used where recent grades are commenced to cater for tangible needs in erection, incognito modifiers and massive duty amalgamation.

Usually, the choice of bitumen grade in a province is depends on climate of the promised site. For hot state climate or meteorological condition, harder grade of bitumen is proposed while softer grade is worthy for cold country atmospheric condition. Whatever an unspecified amount of bitumen requisites alternation in order to 
meet precise requirement. Yet, not all modifiers suitable for all application because each mineral conditioner have its own chemical formation. Commonly, bitumen should be refitted to diminish temperature susceptibility and enhance the ability to stick fast to a surface and cohesive. Consequently, it is desired that this method will not only deliver importance impact in recycling agricultural waste components but also have efficient to minimize the budget and flourish the function of bitumen.

Familiar for its sticky or glue and cohesive quality, bitumen is mostly effective use of in the erection factories.

Bitumen is spread on a surface on road paving because it is viscous when hot, but solid once it cools down. Therefore, Bitumen functionate as the binder/glue for pieces of the aggregate.

The limitless advantage of refined bitumen is used in erection: mainly as a admixture of products used in paving and roofing installation, highways construction and underground water proofing works. In accordance with the conditions of the end use bitumen is produced to specification or precise requirement. This is fulfill either by refining process or mixing.
It is calculated that the running world usage of bitumen is nearly 102 million tonnes per year. On an average $85 \%$ of all the bitumen make from raw materials is usaged as the bonder in asphalt for roads. The main focus of this paper is to establish an overall and comprehensive understanding the actual values of different grade bitumen used in and around Dhaka city, bitumen properties and suggesting suitable type of bitumen in the investigated area.

\section{Test Procedure}

There are various types of tests to determine the properties of bituminous materials. We have performed here five tests such as penetration test, specific test, softening point test, ductility test, solubility test.
a. Penetration test
b. Specific gravity test
c. Softening point test
d. Ductility test
e. Solubility test (Figure 1)

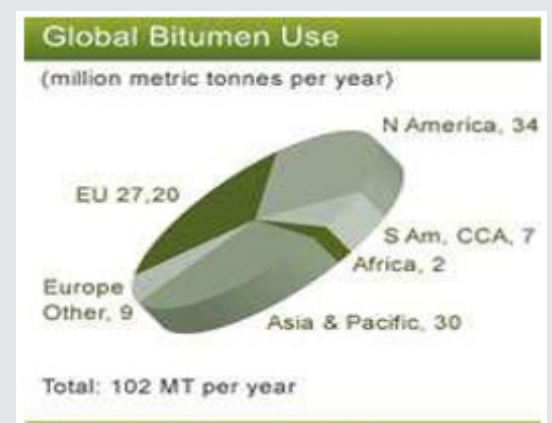

Bitumen Applications:

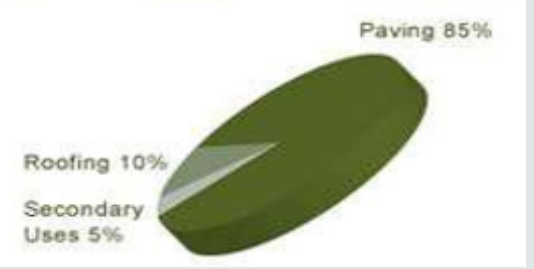

Figure 1: Uses and Applications of Bitumen Globally.

\section{Scope and importance of the above test}

I. Generally, the penetration test is used as a standard unit of consistency and upper grades of penetration suggests flexible firmness.

II. Penetration test is commonly used all around the world for categorizing bituminous materials into various grades.

III. Largely rely on the atmospheric condition and type of erection, bitumen of various penetration grade is used. Normally used grades are enlisted here, such as 30/40, 60/70 and 80/100

IV. Generally, in hot areas, minor penetration values are considered and in colder areas bitumen with upper penetration values are choose.

V. Usually Specific gravity of a bitumen binder is a elementary property which is frequently requisite as an aid in classing binders for use in paving jobs.

VI. Ordinarily specific gravity is also used in recognizing the origin of bitumen binder.

VII. Normally softening point is the temperature at which the bituminous binders have a same viscosity (i.e. the consistency of all the grades will be same at the softening point e.g. if two samples have softening points of $40^{\circ} \mathrm{C}$ and $80^{\circ} \mathrm{C}$ respectively, both will have the same consistency at their softening point.). 
VIII. The test indicates the idea of the temperature at which the bituminous materials attain assure viscosity.

IX. In grossly bitumen with upper softening point may be applied in warmer regions

X. In fact, softening point should be larger than the hottest day temperature, which is anticipated in that area otherwise bitumen may adequately soften and result in bleeding and improvement of ruts.

XI. Tensile strength of bitumen (Ductility test)

XII. Grade of sample (ductility grad)

XIII. Finally, this experiment covers the meanings of the degree of solubility in trichloroethylene of asphalt materials having lower or no mineral substantiality.

\section{Collected Samples}

Our collected samples are indicated below:

a) Sample 1: Penetration Grade 60/70 (from Mirpur road, New Market, Dhaka)

b) Sample 2: Penetration Grade 80/100 (from LGED)

c) Sample 3: Penetration Grade 60/70 (from Panthapath, Dhaka)

\section{Calculation and Analysis of the Experimental Data}

\section{Data Analysis of Penetration Test}

For Sample 1 (Penetration Grade 60/70)

Observations and Results: (Table 1)

Table 1: Data Sheet for Sample 1 of Penetration Test.

\begin{tabular}{|c|c|c|}
\hline \multirow{2}{*}{ Serial No } & \multicolumn{2}{|c|}{ Penetration } \\
\hline & Reading & Mean \\
\hline \multirow{3}{*}{1} & 62 & \multirow{3}{*}{62.67} \\
\hline & 62 & \\
\hline & 64 & \\
\hline \multirow{3}{*}{2} & 64 & \multirow{3}{*}{63.67} \\
\hline & 64 & \\
\hline & 63 & \\
\hline \multirow{3}{*}{3} & 62 & \multirow{3}{*}{63} \\
\hline & 63 & \\
\hline & 64 & \\
\hline
\end{tabular}

Comments: The examination has been operated effectively and the mean penetration value came out to be 64.55. Accordingly, the tables the values ranging from 50 to 149 should have variation of maximum 4. In our case the difference is $67-63=4$ which is equal to 4 so our executed experiment and the penetration value are almost authentic and correct. We accomplished the experiment at room temperature (Figure 2).

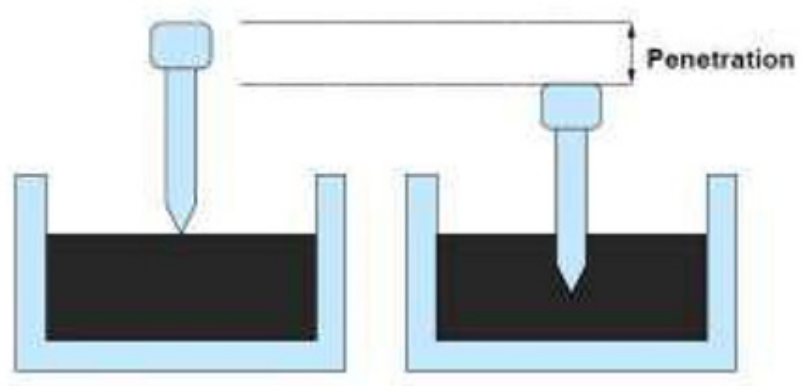

Figure 2: Penetration Test Setup.

For Sample 2 (Penetration Grade 80/100)

Observations and Results: (Table 2)

Table 2: Data Sheet for Sample 2 of Penetration Test.

\begin{tabular}{|c|c|c|}
\hline \multirow{2}{*}{ Serial No } & \multicolumn{2}{|c|}{ Penetration } \\
\hline & Reading & Mean \\
\hline \multirow{3}{*}{1} & 95 & \multirow{3}{*}{95} \\
\hline & 95 & \\
\hline & 95 & \\
\hline \multirow{3}{*}{2} & 93 & \multirow{3}{*}{93.33} \\
\hline & 93 & \\
\hline & 94 & \\
\hline \multirow{3}{*}{3} & 92 & \multirow{3}{*}{92.67} \\
\hline & 93 & \\
\hline & 93 & \\
\hline
\end{tabular}

Comments: The examination has been operated effectively and the mean penetration value came out to be 93.67. In accordance with the tables the values ranging from 50 to 149 should have difference of highest 4 . In our case the difference is $=95-92=3$ which is lesser then 4 so our performed experiment and the penetration value is perfectly correct. We performed the experiment at room temperature.

\section{For Sample 3 (Penetration Grade 60/70)}

\section{Observations and Results: (Table 3)}

Table 3: Data Sheet for Sample 3 of Penetration Test.

\begin{tabular}{|c|c|c|}
\hline \multirow{2}{*}{ Serial No } & \multicolumn{2}{|c|}{ Penetration } \\
\hline & Reading & Mean \\
\hline \multirow{3}{*}{1} & 62 & \multirow{3}{*}{62.67} \\
\hline & 62 & \\
\hline & 64 & \\
\hline \multirow{3}{*}{2} & 64 & \multirow{3}{*}{63.67} \\
\hline & 64 & \\
\hline & 63 & \\
\hline \multirow{3}{*}{3} & 62 & \multirow{3}{*}{63} \\
\hline & 63 & \\
\hline & 64 & \\
\hline
\end{tabular}


Comments: The examination has been operated with success and the mean penetration value came out to be 63.11. According to the tables the values ranging from 50 to 149 should have variation of maximum 4 . In our case the variation is $64-62=2$ which is lesser to 4 hence our accomplished experiment and the penetration value is correct and genuine. We executed the experiment at room temperature.

\section{Data Analysis of Specific Gravity Test}

For Sample 1 (Penetration Grade 60/70)

Mass of Pycnometer (+ stopper), A = 21gm
Mass of Pycnometer filled with water, $B=77 \mathrm{gm}$

Mass of Pycnometer partially filled with bitumen, $C=59 \mathrm{gm}$

Mass of Pycnometer + asphalt + water, D = 78gm

Specific Gravity $=\frac{(C-A)}{(B-A)-(D-C)}$

\section{Observations and Results: (Table 4)}

Comments: The test has been executed with success and the specific gravity determined is 1.03 which is in the range of 1.00 to 1.05. So it is acceptable. There were no bubbles in the pycnometer so chance of mistake was dispelled and then the value become correct.

Table 4: Data Sheet for Sample 1 of Specific Gravity Test.

\begin{tabular}{|c|c|c|c|c|c|}
\hline \multirow{2}{*}{ Sample No } & \multicolumn{3}{|c|}{ Weights } & $\begin{array}{c}\text { Specific Gravity = } \\
\text { (C-A)(B-A)-(D-C) }\end{array}$ \\
\hline \multirow{2}{*}{1} & Pycnometer, (A) gm & $\begin{array}{c}\text { Pycnometer+Water, } \\
\text { (B) gm }\end{array}$ & $\begin{array}{c}\text { Pycnometer } \\
\text { +Bitumen, (C) Gm }\end{array}$ & $\begin{array}{c}\text { Pycnometer + } \\
\text { Bitumen+Water, (D) } \\
\text { Gm }\end{array}$ & $\begin{array}{c}1.027 \\
=1.03\end{array}$ \\
\cline { 2 - 5 } & 21 & 77 & 59 & 78 \\
\end{tabular}

\section{For Sample 2 (Penetration Grade 80/100)}

Mass of Pycnometer (+ stopper), A = 40gm

Mass of Pycnometer filled with water, B = 94gm
Mass of Pycnometer partially filled with bitumen, $\mathrm{C}=80 \mathrm{gm}$

Mass of Pycnometer + asphalt + water, D = 95gm

Specific Gravity $=\frac{(C-A)}{(B-A)-(D-C)}$

\section{Observations and Results: (Table 5)}

Table 5: Data Sheet for Sample 2 of Specific Gravity Test.

\begin{tabular}{|c|c|c|c|c|c|}
\hline \multirow{2}{*}{ Sample No } & \multicolumn{3}{|c|}{ Weights } & $\begin{array}{c}\text { Specific Gravity = } \\
\text { (C-A)(B-A)-(D-C) }\end{array}$ \\
\hline \multirow{2}{*}{1} & Pycnometer, (A) Gm & $\begin{array}{c}\text { Pycnometer +Water, } \\
\text { (B) gm }\end{array}$ & $\begin{array}{c}\text { Pycnometer } \\
\text { +Bitumen, (C) Gm }\end{array}$ & $\begin{array}{c}\text { Pycnometer + } \\
\text { Bitumen+Water,(D) } \\
\text { Gm }\end{array}$ & $\begin{array}{c}1.025 \\
=1.03\end{array}$ \\
\cline { 2 - 6 } & 40 & 94 & 80 & 95 \\
\hline
\end{tabular}

Comments: Since the test has been executed successfully, the specific gravity determined as 1.03 which is in the range of 1.01 to 1.06. So, it is perfectly acceptable. There were no single bubbles in the pycnometer so the possibility of error was eliminated and thus the value become correct.

\section{For Sample 3 (Penetration Grade 60/70)}

Mass of Pycnometer (+ stopper), A = 21gm

\section{Observation and results: (Table 6)}

Table 6: Data Sheet for Sample 3 of Specific Gravity Test.

\begin{tabular}{|c|c|c|c|c|c|}
\hline \multirow{2}{*}{ Sample No } & \multicolumn{3}{|c|}{ Weights } & Specific Gravity = \\
\hline \multirow{2}{*}{1} & Pycnometer, (A) Gm & $\begin{array}{c}\text { Pycnometer +Water, } \\
\text { (B) gm }\end{array}$ & $\begin{array}{c}\text { Pycnometer } \\
\text { +Bitumen, (C) Gm }\end{array}$ & $\begin{array}{c}\text { Pycnometer + } \\
\text { Bitumen+Water,(D) } \\
\text { Gm }\end{array}$ & $\begin{array}{c}1.024 \\
=1.02\end{array}$ \\
\cline { 2 - 5 } & 21 & 78 & 63 & 79 \\
\end{tabular}

Mass of Pycnometer filled with water, $\mathrm{B}=78 \mathrm{gm}$

Mass of Pycnometer partially filled with bitumen, $C=63 \mathrm{gm}$

Mass of Pycnometer + asphalt + water, $D=79 \mathrm{gm}$

Specific Gravity $=\frac{(C-A)}{(B-A)-(D-C)}$ 
Comments: The experimental test has been finished in a successful manner and the specific gravity consider as 1.02 which is in the range of 1.00 to 1.05 . So, it is acceptable which is perfectly correct. There were no bubbles in the pycnometer so chance of mistake was eliminated and thus the value being correct.

\section{Data Analysis of Softening Point Test (Figure 3)}

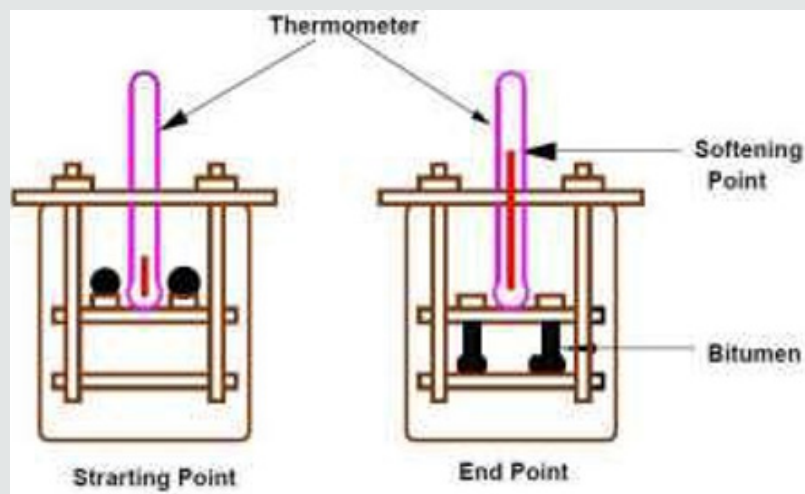

Figure 3: Softening Point Test Setup.

\section{For sample 1 (Penetration Grade 60/70)}

Observations and Results: (Table 7)

Table 7: Data Sheet for Sample 1 of Softening Point Test.

\begin{tabular}{|c|c|c|}
\hline \multirow{2}{*}{ Serial No. } & Softening Point & Mean \\
\cline { 2 - 3 } & $\left({ }^{\circ} \mathbf{C}\right)$ & $\left({ }^{\circ} \mathbf{C}\right)$ \\
\hline 1 & $46.4{ }^{\circ} \mathrm{C}$ & \multirow{2}{*}{$46.5^{\circ} \mathrm{C}$} \\
\hline 2 & $46.6^{\circ} \mathrm{C}$ & \\
\hline
\end{tabular}

Comments: The experiment has been performed successfully and the softening point came out to be $46.5^{\circ} \mathrm{C}$ which is not in the range of $49^{\circ} \mathrm{C}$ to $56^{\circ} \mathrm{C}$. So it is not acceptable.

For Sample 2 (Penetration Grade 80/100)

Observations and Results: (Table 8)

Table 8: Data Sheet for Sample 2 of Softening Point Test.

\begin{tabular}{|c|c|c|}
\hline \multirow{2}{*}{ Serial No. } & Softening Point & Mean \\
\cline { 2 - 3 } & $\left({ }^{\circ} \mathbf{C}\right)$ & $\left({ }^{\circ} \mathbf{C}\right)$ \\
\hline 1 & $45.7^{\circ} \mathrm{C}$ & \multirow{2}{*}{$45.7^{\circ} \mathrm{C}$} \\
\hline 2 & $45.7^{\circ} \mathrm{C}$ & \\
\hline
\end{tabular}

Comments: The experiment has been performed successfully and the softening point came out to be $45.7^{\circ} \mathrm{C}$ which is not in the range of $45^{\circ} \mathrm{C}$ to $52^{\circ} \mathrm{C}$. So, it is acceptable which is perfectly correct.

\section{For Sample 3 (Penetration Grade 60/70)}

\section{Observations and Results: (Table 9)}

Comments: The test has been executed in a successful manner and the softening point came out to be $49.2^{\circ} \mathrm{C}$ which is not in the range of $49^{\circ} \mathrm{C}$ to $56^{\circ} \mathrm{C}$. So, it is adoptable which is absolutely correct.
Table 9: Data Sheet for Sample 3 of Softening Point Test.

\begin{tabular}{|c|c|c|}
\hline \multirow{2}{*}{ Serial No. } & Softening Point & Mean \\
\cline { 2 - 3 } & $\left({ }^{\circ} \mathbf{C}\right)$ & $\left({ }^{\circ} \mathbf{C}\right)$ \\
\hline 1 & $49 .{ }^{\circ} \mathrm{C}$ & \multirow{2}{*}{$49.2^{\circ} \mathrm{C}$} \\
\hline 2 & $49.2^{\circ} \mathrm{C}$ & \\
\hline
\end{tabular}

\section{Data Analysis of Ductility Test}

For Sample 1 (Penetration Grade 60/70) (Figure 4)

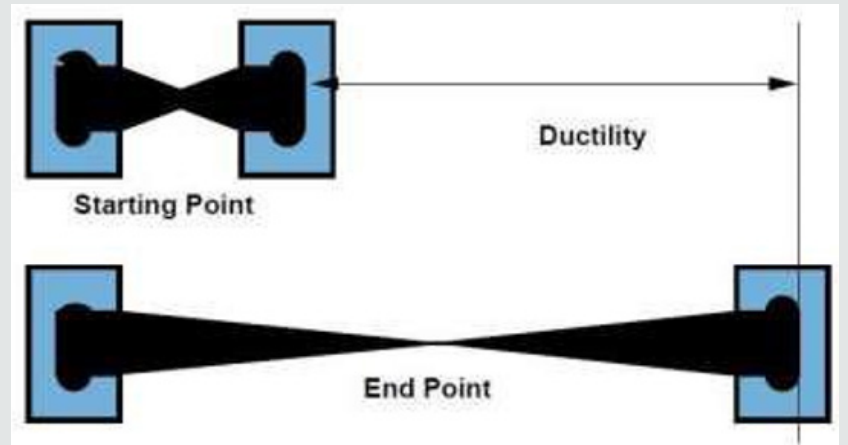

Figure 4: Ductility Test.

\section{Observations and Results}

Grade of Bitumen $=60 / 70$

Test Temperature $=27^{\circ} \mathrm{C}$

Ductility Value $=97 \mathrm{~cm}$

Comments: As the Ductility test has been accomplished perfectly, the ductility value has been counted as $97 \mathrm{~cm}$. The ASTM D-113 for $60 / 70$ grade the value of Ductility $=100 \mathrm{~min}$. Temperature was not maintained in the laboratory so the value may varies at 25 ${ }^{\circ} \mathrm{C}$ as we accomplished at the Laboratory temperature.

\section{For Sample 2 (Penetration Grade 80/100)}

Observations and Results

Grade of Bitumen = 80/100

Test Temperature $=25^{\circ} \mathrm{C}$

Ductility Value $=106 \mathrm{~cm}$

Comments: The Ductility test has been executed perfectly and the ductility value has been computed as $105 \mathrm{~cm}$. The ASTM D-113 for $60 / 70$ grade the value of Ductility $=100 \mathrm{~min}$. So, it is accepted which is perfectly correct.

\section{For Sample 3 (Penetration Grade 60/70)}

Observations and results

Grade of Bitumen $=60 / 70$

Test Temperature $=260 \mathrm{C}$

Ductility Value $=102 \mathrm{~cm}$ 
Comments: As the Ductility test has been executed perfectly, the ductility value has been counted as $102 \mathrm{~cm}$ which is perfectly correct. The ASTM D-113 for 60/70 grade the value of Ductility $=100 \mathrm{~min}$. Temperature was not maintained in the laboratory so the value may differ at $25^{\circ} \mathrm{C}$ as we performed at the Laboratory temperature.

\section{Data Analysis of Solubility Test}

\section{For Sample 1 (Penetration Grade 60/70)}

Total weight of insoluble, $A=0.15 \mathrm{gm}$

Total weight of sample, $B=2.1 \mathrm{gm}$

Insoluble, percent $=(\mathrm{A} / \mathrm{B}) * 100=(0.15 / 2.1) * 100=7.14 \%$

Soluble, percent $=100-\left[(\mathrm{A} / \mathrm{B})^{*} 100\right]=100-7.14=92.86 \%$

Result: The solubility of the bitumen is 92.86 percent

\section{For Sample 2 (Penetration Grade 80/100)}

Total weight of insoluble, $A=0.10 \mathrm{gm}$

Total weight of sample, $B=2.0 \mathrm{gm}$

Insoluble, percent $=(\mathrm{A} / \mathrm{B})^{*} 100=(0.10 / 2.0) * 100=5.0 \%$

Soluble, percent $=100-\left[(\mathrm{A} / \mathrm{B})^{*} 100\right]=100-5.0=95 \%$

Result: The solubility of the bitumen is 95 percent.

\section{For Sample 3 (Penetration Grade 60/70)}

Total weight of insoluble, $A=0.12 \mathrm{gm}$

Total weight of sample, $B=2.0 \mathrm{gm}$

Insoluble, percent $=(\mathrm{A} / \mathrm{B}) * 100=(0.12 / 2.0) * 100=6 \%$

Soluble, percent $=100-[(A / B) * 100]=100-6.0=94 \%$

Result: The solubility of the bitumen is 94 percent

\section{Comparison Between Standard Values and Experimental Values of Different Grade Bitumen}

(Table $10 \& 11$ )

Table 10: Specification of Penetration Grade Bitumen.

\begin{tabular}{|c|c|c|c|}
\hline Property & Range & & Standard \\
\hline & BITUMEN 80/100 & BITUMEN 60/70 & ASSTM/AASHTO \\
\hline Specific Gravity @ $25 / 25^{\circ} \mathrm{C}$ & $1.01 / 1.06$ & $1.00 / 1.05$ & D-70 \\
\hline Penetration @ $25^{\circ} \mathrm{C}$ & $80 / 100$ & $60 / 70$ & D-5 \\
\hline Softening Point ${ }^{\circ} \mathrm{C}$ & $45 / 52$ & $49 / 56$ & D-36 \\
\hline Ductility @ $25^{\circ} \mathrm{C} \mathrm{CMS}$ & $100 \mathrm{MIN}$ & $100 \mathrm{MIN}$ & D-113 \\
\hline Solubility in CS@ (wt)\% & $99.5 \mathrm{MAX}$ & $99.5 \mathrm{MAX}$ & D-4 \\
\hline
\end{tabular}

Table 11: Experimental Value of Different Penetration Grade Bitumen.

\begin{tabular}{|c|c|c|c|c|}
\hline \multirow[t]{2}{*}{ Property } & \multicolumn{3}{|c|}{ Range } & \multirow{2}{*}{$\begin{array}{c}\text { Standard } \\
\text { ASSTM/AASHTO }\end{array}$} \\
\hline & BITUMEN 60/70 Sample 1 & BITUMEN 80/100 sample 2 & BITUMEN $60 / 70$ sample 3 & \\
\hline Penetration@ @25든 & 64.55 & 93.67 & 63.11 & D-5 \\
\hline Specific Gravity @ 25/25 ${ }^{\circ} \mathrm{C}$ & 1.03 & 1.03 & 1.02 & $\mathrm{D}-70$ \\
\hline Softening Point ${ }^{\circ} \mathrm{C}$ & 45.5 & 45.7 & 49.2 & D-36 \\
\hline Ductility@25ㄷCMS & 97 & 106 & 102 & D-113 \\
\hline Solubility in CS@ (wt)\% & 92.86 & 95 & 94 & D-4 \\
\hline
\end{tabular}

\section{Conclusion}

During the study period we collected three samples. Two of these are penetration grade $60 / 70$ and one is penetration grade $80 / 100$. In the lab we performed five tests on bitumen to assess its consistency, gradation, temperature susceptibility, and safety. These tests are: penetration test, ductility test, softening point test, specific gravity test and solubility test. We determined and evaluated different properties of bituminous materials throughout these tests. From these properties of bituminous materials (such as hardness or softness, tensile properties, solubility) we can easily select a suitable grade of bitumen for roadway construction according to the surrounding conditions and climates. From our study we prefer the Penetration Grade 80/100 which is most suitable for transportation projects in and around Dhaka city. Before Applying this Grade of Bitumen pavement should be harden [1-9].

\section{References}

1. Piyush Kumar Singh, Suman SK (2018) Influence of graphite on the physical and rheological properties of bituminous binder before and after short-term ageing. Construction and Building Materials 192: 866873 . 
2. Imraan Akhalwaya (2018) Retarding crack reflection using bitumenrubber seals and overlays - historic overview of csir research. General science, engineering \& technology.

3. Md Tareq Rahman (2017) Use of waste cooking oil, tire rubber powder and palm oil fuel ash in partial replacement of bitumen. Construction and Building Materials 150: 95-104.

4. Md Tareq Rahman, Mohd. Rosli Hainin, Wan Azelee Wan Abu Bakar, Md Maniruzzaman A Aziz (2016) Alternative binders for flexible pavement. Construction and Building Material 84(1): 315-319.

5. Md Tareq Rahman. Use of Modified Bitumen in Highway Construction.

6. Oladipupo olafusi, Bamidele IO.Dahunsi, Olufemi S Awogboro, Mutiu
Akinpelu (2013) Investigation of the Properties of Pure Water sachet modified bitumen. Civil and Environmental research 3(2).

7. Fernando Martinez Soto (2009) Design optimization of bituminous rubber- mixtures in railway sub-ballast, pp. 1-7.

8. Mohamed Rehan Karim (2013) Investigating the rheological properties of crumb rubber modified bitumen and its correlation with temperature susceptibility. Materials Research 16(1).

9. Muhammad Junaid, Muhammad Irfan, Sarfraz Ahmed Yasir Ali (2018) Effect of binder grade on performance parameters of asphaltic concrete paving mixtures. International Journal of Pavement Research and Technology 11(5): 435-444.

\section{(c) $(9$ \\ This work is licensed under Creative Commons Attribution 4.0 License}

To Submit Your Article Click Here:

Submit Article

DOI: 10.32474 /TCEIA.2019.03.000159

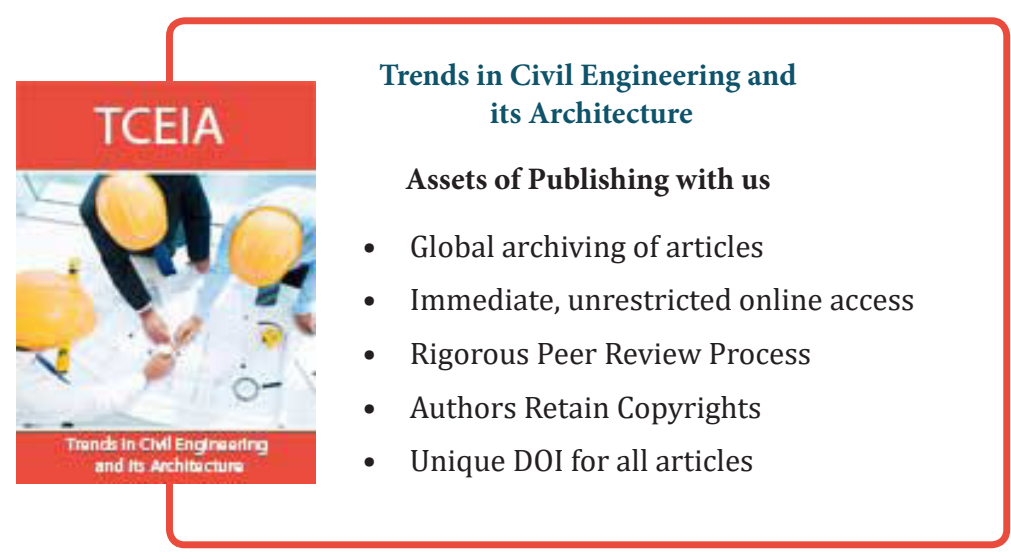

